Florida International University FIU Digital Commons

$6-25-2018$

\title{
Imaginative Ecosystems: Clamoring for Visibility and Opacity in Miami's Climate Justice Movement
}

Laura Maria Aguirre

venndiagrams@gmail.com

DOI: $10.25148 /$ etd.FIDC006851

Follow this and additional works at: https://digitalcommons.fiu.edu/etd

Part of the English Language and Literature Commons

\section{Recommended Citation}

Aguirre, Laura Maria, "Imaginative Ecosystems: Clamoring for Visibility and Opacity in Miami's Climate Justice Movement" (2018). FIU Electronic Theses and Dissertations. 3783.

https://digitalcommons.fiu.edu/etd/3783

This work is brought to you for free and open access by the University Graduate School at FIU Digital Commons. It has been accepted for inclusion in FIU Electronic Theses and Dissertations by an authorized administrator of FIU Digital Commons. For more information, please contact dcc@fiu.edu. 


\title{
FLORIDA INTERNATIONAL UNIVERSITY \\ Miami, Florida
}

\section{IMAGINATIVE ECOSYSTEMS: CLAMORING FOR VISIBILITY AND OPACITY IN MIAMI’S CLIMATE JUSTICE MOVEMENT}

\author{
A thesis submitted in partial fulfillment of \\ the requirements for the degree of \\ MASTER OF ARTS \\ in \\ ENGLISH \\ by \\ Laura Aguirre
}


To: Dean Michael R. Heithaus

College of Arts, Sciences and Education

This thesis, written by Laura Aguirre, and entitled Imaginative Ecosystems: Clamoring for Visibility and Opacity in Miami's Climate Justice Movement, having been approved in respect to style and intellectual content, is referred to you for judgment.

We have read this thesis and recommend that it be approved.

Paul Feigenbaum

Heather Russell

Ana Luszczynska, Major Professor

Date of Defense: June 25, 2018

The thesis of Laura Aguirre is approved.

Dean Michael R. Heithaus

College of Arts, Sciences and Education

Andrés G. Gil

Vice President for Research and Economic Development and Dean of the University Graduate School

Florida International University, 2018 


\section{DEDICATION}

"To plant a tree is an act of intergenerational optimism, a selfless act at once practical and utopian, an investment in a communal future the planter will not see; to plant a tree is to offer shade to unborn strangers."

- Rob Nixon

To all those who nurture better futures through their acts of optimism. 


\section{ACKNOWLEDGMENTS}

I am grateful to and gladdened by the community of people that have made this project possible - family members, friends, professors, classmates, coworkers, neighbors, acquaintances, chance encounters. Thank you for enabling me to write about hope by sharing yours with me. 


\section{ABSTRACT OF THE THESIS \\ IMAGINATIVE ECOSYSTEMS: CLAMORING FOR VISIBILITY AND OPACITY \\ IN MIAMI'S CLIMATE JUSTICE MOVEMENT}

by

Laura Aguirre

Florida International University, 2018

Miami, Florida

\section{Professor Ana Luszczynska Major Professor}

Though Miami is one of the places most vulnerable to climate change, climate change threats are not at the forefront of most citizen's worries. Furthermore, though all Miamians are vulnerable in the face of climate change, they are stratified into communities that will bear the consequences of that threat with different intensities, including frontline communities that struggle to bring visibility to themselves and their concerns. Activist-citizens need to connect the dots between ethical, social, political, economic, and environmental issues and create kinship networks that break through compartmentalized communities. The purpose of this thesis is to explore how climate justice initiatives, like the Miami People's Climate March, catalyze action and subvert institutional narratives that preclude change by collaboratively reimagining communities as communal ecosystems. These initiatives foreground the relationality between human and nonhuman subjects, demand visibility for frontline communities, and unite diverse populations in solidarity while simultaneously acknowledging and celebrating difference. 


\section{TABLE OF CONTENTS}

CHAPTER

PAGE

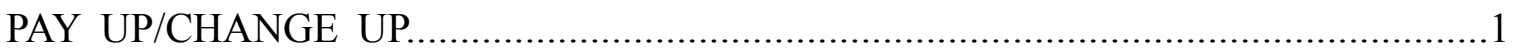

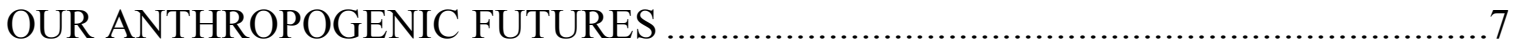

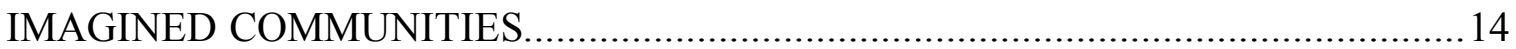

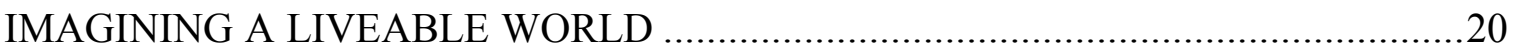

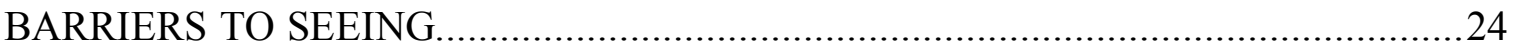

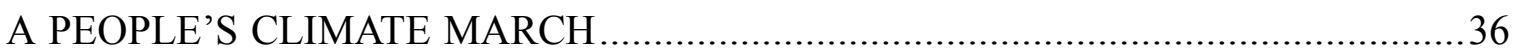

LIVING IN RELATION; CLAMORING FOR OPACITY .........................................43

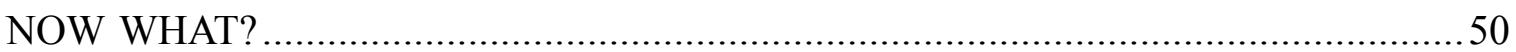

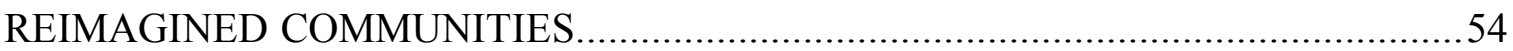

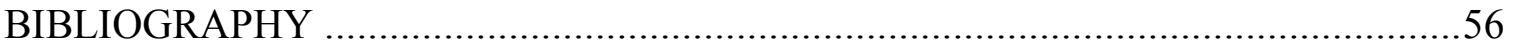




\section{PAY UP/CHANGE UP}

In March, five new billboards greeted commuters on Miami’s major highways.

On each, a black background faded into an image of a flooded neighborhood.

Superimposed over that background, in stark, white letters, was this question: "When will climate polluters pay their fair share?" The billboards were meant to introduce Miami residents to the Pay Up Climate Polluter's Campaign, launched through a partnership between the grassroots Miami Climate Alliance (MCA) and the Center for Climate Integrity (CCI), one arm of the Washington DC based Institute for Governance and Sustainable Development (IGSD). Among other goals, both groups aim to promote environmental sustainability, resilience, and justice through policy wins.

The campaign, which might be viewed as progressive or subversive, but which is certainly dramatic, urges residents to hold climate polluters - oil, gas, and power companies, according to their website - accountable for the damage they've caused by suing the companies ("Pay Up"). Drivers who visited MiamiClimateCosts.com, as they were directed, would have learned about this initiative. (I can't help but wonder if the drivers who didn't visit the website sat guiltily in bumper to bumper traffic, roped into a standstill of thousands of exhaust-emitting vehicles, irritated by a perceived accusation).

If climate polluters are going to pay up, someone needs to serve them an itemized bill. So in April, Maggie Fernandez, a Miami-based climate activist and a founding member of the MCA, spoke in front of Miami's Sea Level Rise Committee and asked them to assess how much climate resilience and adaptation initiatives were costing taxpayers. Fernandez clarified that she wasn't asking the board to file a lawsuit or to support her campaign. What she wanted from them was data. In addition, she also spoke 
frankly about her dismay that the faces in front of her were so dissimilar to Miami's population; the Sea Level Rise Committee had nine members, eight of whom were white men (including Hispanics), and one of whom, Kilan Ashad-Bishop, was a black woman. She also registered her frustration about the board's pace of action, which she thought did not match the exigency of Miami's climate change problems.

The idea was not well-received by all, and was particularly poorly received by board member Reinaldo Borges, an architect, who was personally insulted by her commentary and disgruntled by her utopian ideals. Borges suggested that Fernandez's aims failed to align with the pragmatic challenges the committee faced, including the fact that the Sea Level Rise Committee was organized to address exactly that, and not to tackle climate change at large. He responded to Fernandez, saying "I wish your energy and enthusiasm toward changing the world were a little more focused" (@BillyCorben) and when Fernandez tried to keep speaking, once to express her annoyance with his "mansplaining", he sharpened his retorts.

"If you don't want to listen then go home and don't worry about showing up here again" he told her, before asserting "I don't want to spend an ounce of my energy here on this planet fighting the polluters, ok, because I think we all are that” (@BillyCorben). He announced that it was a waste of time to criticize the "mix and equity balance of the community" and urged her to focus on solutions that would address the issues Miami is already facing and will continue to face in the future (@BillyCorben).

He capped off his outburst by qualifying his anger: "We're all volunteers here. We're all trying to give back to the community. We all love Miami as much as you think 
you like Miami and love Miami, but I find your presentation, your approach, offensive, misguided, and a waste of energy" (@BillyCorben).

Fernandez left the meeting in tears and texted Miami’s mayor Francis Suarez that she had never been treated so poorly and was considering filing a complaint. Local media outlets picked up the story - articles ran in the Miami Herald, Miami New Times, and WLRN (South Florida's NPR Station), as well as being included in local newsletter The New Tropic's daily roundup of important articles.

Most media outlets vilified Borges' behavior. WLRN wrote that he "publically berated" her, the Miami Herald that he "turned ugly", and the Miami New Times that he "lobbed insults at [her]... all because she asked the committee to push harder to fight climate change and criticized the group for a lack of diversity" (Stein; Harris; Ianelli). Billy Corben, documentarist and director of Cocaine Cowboys, procured and tweeted footage of Borges' comments from the meeting, suggestively mentioning Mayor Suarez in a reminder that Borges had been appointed by the mayor, who had yet to ask him to resign. In response, Mayor Suarez expressed his wish to replace board members whose terms were up with more diverse representatives. He specifically called out Borges, writing, "If I were him, I would resign, and think he should."

A few were sympathetic to Borges, including Jeff Goodell, author of The Water Will Come, which examines sea-level rise in Miami, among other places. In response to Corben, he tweeted, "I wasn't at meeting \& am not condoning how @borgesarchitect handled this, but will say he is one of most knowledgeable and committed people I've met in Miami \& has done great work to advance public awareness of SLR risk. Maybe a little perspective (\& forgiveness) is in order?” (@BillyCorben). 
The confrontation was galvanizing for Fernandez' cause. The outburst catalyzed conversations about diversity, accountability, and urgency. People were (not for the first time) talking about how, in Miami, sea-level rise and climate change cannot be discussed as mutually exclusive issues. Under this public scrutiny, city officials and residents questioned the scope and mission of the Sea Level Rise Committee, resulting in calls for a more diverse committee operating with broader resilience goals.

The argument is only one, small friction point among many in any project so large, daunting, and unimaginable as a response to climate change. We are living in the Anthropocene, the name given to this era when humans exert the most influence out of any beings on the climate and environment. We are aware of and grappling with what Timothy Morton calls hyperobjects - things that are massively distributed in time and space relative to humans. Climate change is one such hyperobject, as is radiation, the global supply of oil, or oceanic pollution.

Consider pollution: J.R. McNeill, in his environmental history of the twentieth century, Something New Under the Sun, notes that oceanic pollution is difficult to combat for two reasons. Firstly, the ocean is envisioned as so vast, so endless, that it is not possible to truly harm it; people assume that the ocean can absorb pollutants and litter without being fundamentally changed. (In related news, this April a study reported that a plastic bag had been found at the bottom of the Mariana trench, 36,000 feet below the surface of the water). Secondly, the ocean is seen as an anational abstract. It embraces many borders and nations, channeling through various sets of laws and regulations. We never see the ocean in its entirety. We experience specific sites of the ocean, most often in the liminal spaces of beaches or estuaries or, here in Miami, mangrove forests. Those 
spaces are subject to national and local laws, but countries and cities feel responsibility for coastlines, not ocean.

The challenges that McNeill mentions are the challenges that all hyperobjects pose. They are dizzyingly complicated systems, whose origins and futures stretch so far away from us that it is nearly impossible for us to hold them in our minds. We see hyperobjects only in phases and pieces, but even when we don't see them, they are there, viscously clinging to our lives, reminding us that our siloed local existences are abstractions that we have created, that we are all enmeshed in countless ways.

Hyperobjects test our grit, our empathy, our capacity to act. And they test our imaginations.

Some might find it ridiculous to envision a future where bands of incensed citizens stand up to Florida Power and Light (FPL) or where municipalities wrestle with global issues like climate change. Some might be even further amused by the thought of those groups working in unison - a clashing of stereotypes, in which a crusade of loftyminded social justice warriors work alongside a conglomerate of stodgy, tunnel-visioned bureaucrats.

But the world is changing, whether you like it or not, and how people live with one another in the world will change too. Donna J. Haraway writes that "We - all of us on Terra - live in disturbing times, mixed-up times, troubling and turbid times" (1). She says our "task is to make kin in lines of inventive connection as a practice of learning to live and die well with each other in a thick present" (1).

Can we remain civil with the water lapping at our heels, trying to save the places we love so much, and already feeling the pain of loss as those places recede under seas 
we know will roll in? (Do we need to remain civil, even? Isn't there, as we've seen, tremendous potential for change in explosive situations?) Do we have sufficient imagination to, when utopian ideals and pragmatic policies jostle for space in the same arena, envision them not as contenders, but as complements? How do we live, and who do we live with, as kin, in these thick and murky times? 


\section{OUR ANTHROPOGENIC FUTURES}

As I was scrolling through Netflix one day, I found a short animated film by Kunio Katō, La Maison en Petits Cubes (The House of Tiny Cubes) that offered one vision for a watery future. In a land of rising waters, a widowed man keeps living above the tide by constructing successive stories of tiny cubes atop each other, each one linked to the one below by a hatch. After he accidentally drops his pipe through the hatch, he begins diving through the rooms, swimming in reverse chronology, encountering the sedimented layers of his life - the water through which he moves is both what allows him to navigate through his past and what sequesters him from it, what allows him to and obstructs him from inhabiting that memorial space. He is there, suspended in history and memory, but only fleetingly - his air supply is limited, the gauge on the tank which holds his oxygen an empirical reminder that he is only sojourning in these places.

When I watched the film, I had just recently read about the park that circumferences Grüner See (Green Lake) in Tragoess, Austria. The lake floods each summer; until recently, divers could drop into a world both aquatic and terrestrial, navigating between trees and over park benches, gliding above pebbly footpaths and lush expanses of lawn. (It was subsequently closed to divers after it became a popular destination because the office of tourism, concerned about pollution and disturbed sediment, warned that the lake might lose its signature emerald color). Photos of the divers are both alluring and disaffecting. In one, a tree arcs over a white path, lowering its silhouette onto the green grasses that border the trail. The aquamarine background suggests a clear sky, but the sky textures at the top of the photo, clotting into ripples of 
shadow and diffused patches of light. A diver is suspended by the tree branch, blue fins frozen at the poles of their cyclical propulsion. Bubbles rise from the tank and gather in a foamy cloud near the surface. It is only this last detail that brings the surreal image into immediacy, that forces acknowledgement of the familiar and inescapable and real necessity of breathing in this speculative landscape.

Images from the film and of the lake resurfaced in my mind weeks later when I was at a Sip of Science event on the Miami Science Barge. Ajani Stewart from the City of Miami's Office of Resilience uttered this unpopular, but eminently true claim: we will, he said, in this city, cede land back to the sea.

I suppose he might have framed this as a concession to preserve some sense of agency (which is what we have truly ceded, and long ago, to corporations and their political surrogates), as though in some negotiation room Miami government officials met with oceanic delegates (merpeople, half-wild hair entwined with seaweed, tails clamped by decorative crustaceans; gods of myth, tridents left begrudgingly behind after triggering the metal detectors...) and hashed out the details of the exchange, in which Miami loses its coastal properties, gives them back to silt and salt, and the ocean expands in an age of global warming (or worse, because more accurate, human-induced climate change) without the consent of Florida's governor Rick Scott, who presumably is distressed that banning the phrase "climate change" from government proceedings did not, actually, preclude its occurrence (though Scott denies these allegations).

And despite this, people keep building. In March of 2016, Jessica Pressler wrote a piece for New York Magazine about a new construction on South Beach, the Faena Hotel, which set records for the sale of its sixty-million dollar penthouse units. The hotel is 
glitteringly opulent, adorned with extravagances - a taxidermied peacock, Pablo Escobar's palm tree. Chief among these ornaments is a work of art by Damien Hirst. Emblazoned across the environmental backdrop of dune and grass and cloud, a gilded mammoth skeleton occupies a gilded cage, immortalized in a space it never roamed, a burnished emblem of modernity - what can be disinterred, appropriated, repurposed, transplanted (to some: scoured of scientific and historical significance, commodified and commercialized; to others: liberated from expected meanings, occupying the vibrant and necessary intersection of the aesthetic and the capitalistic). What will happen in the coming years, Pressler muses, when the sea level rises and the waters come to reclaim the mammoth? If it survives will it, "thousands of years from now, be plowed from the mud by some other beings, who will say the equivalent of: What the fuck is this?"

\section{What the fuck is this?}

This is not a question that belongs buried in a distant future, one that our vaguely humanoid descendants or extraterrestrial visitors must confront as they dredge the watery surface of the planet and survey the puzzling artifacts of the $20^{\text {th }}$ and $21^{\text {st }}$ century, the gilded mammoths and styrofoam packaging and plastic bath beads and the skeletons of giant, genetically mutated, factory-farmed poultry and the derelict oil rigs and the decaying pipelines.

They sent people to the moon. They grew a sheep in an artificial womb. They didn't see this coming?

There are, though, a host of people who do see it coming. The Yale Program on Climate Communication reported that as of October, 2017, seven in ten Americans believe climate change is happening. However, only about half of Americans believe 
global warming is mostly caused by humans, and only one in seven Americans

understands that "nearly all climate scientists (more than 90\%) are convinced that humancaused global warming is happening". Most Americans say they "rarely" or "never" discuss global warming with friends or family. Considering that there are those who have seen it coming for ages and who have worked tirelessly to educate others about and create policies to mitigate human-induced climate change, there's a lot of catching-up to do. Still, all these numbers constitute an upward trend from past reports, and "the percentage of Americans that are very worried about global warming has more than doubled since its lowest point in 2011" (Leiserowitz).

At this point though, even total carbon neutrality cannot stop the inexorable forces that have been set in motion. According to the latest Intergovernmental Panel on Climate Change (IPCC) report, "surface temperature is projected to rise over the 21 st century under all assessed emission scenarios" (8). The report asserts that "many aspects of climate change and associated impacts will continue for centuries, even if anthropogenic emissions of greenhouse gases are stopped" (16). Even if the global community can collaboratively keep $\mathrm{CO} 2$ levels at no more than $2^{\circ}$ above pre-industrial levels (a mostly unrealizable but ideal goal, and the goal around which the Paris Climate Agreement was organized) climate change and its effects will continue hundreds to thousands of years into the future. The IPCC maintains that "it is virtually certain that global mean sea level rise will continue for many centuries beyond 2100, with the amount of rise dependent on future emissions" (16).

In other words, some of us are living in and continuing to build what will one day be underwater museums, fashioning memorials that will one day bear witness to our 
inability to heed science, alter policy, and reshape industry to avoid exacerbating ongoing climate change.

I mentioned this one day at happy hour. The table buzzed with excitement. Some found the surreal prospect alluring, ensorcelled and haunted by the prospect of South Beach as another Grüner See, with divers gliding through a shallowly submerged Art Deco landscape. (Imaginations cannot resist these speculative wonderings; Jeff Goodell opens The Water Will Come with dramatic depictions of an inundated future Miami, a city gone to drug-runners, given over to crocodiles, and then, finally, opened up to divers who could "explore the great wreckage of an American city") (8). The exercise bloomed with visions of warm, sunstrewn waters cradling buildings gone to coral reef, hybridized structures of concrete and polyps, dormant neon signs and flashing tropical fish.

Others immediately began envisioning a profitable tourism venture - part dive shop, part Miami history tour, part spectacle (A Thalassic Park that reinscribes the errors of the Michael Crichton novel from which the horrible pun originates: "Your scientists were so preoccupied with whether they could, they didn't stop to think if they should.") Some viewed the tourism venture not as an exercise in greed, but as an exercise in adaptation. When the ocean rolls in, old employment opportunities are submerged, but, simultaneously, new opportunities emerge. Why lament the past, or the inevitable future? Why not, with amphibian flexibility, slide smoothly from one environment into the other - no one will really have to leave Key Biscayne or Miami Beach, so long as they have a wetsuit, a skiff, and a keen business acumen.

Still others dismissed the idea, casually tossing it aside, hopes buoyantly and firmly fixed on the insolvent abstract promise that someone, sometime, will figure out 
how to make it work. Miami will be saved, because it is too vigorous, too sultry, too significant, too populated to lose or abandon. Perhaps Miami will become the Venice of the Tropics, robbing the then-inundated Conch Republic of its distinction as the southernmost point of the United States. We can elevate streets, build on stilts, replace buses with powerboats, invest in pumps and dikes and seawalls. (But the limestone betrays this optimism, because the sea rises below Miami as well, and into the Biscayne Bay aquifer, and we cannot change the stone Miami was built on).

Others shrugged it off, not ignoring the threat of sea level rise, but accepting it with the stoic composure only afforded to those who will not bear the brunt of the suffering. So we build with tiny cubes; each time the water rises, we add another cube. Okay. (These are those who, in the backs of their minds know, that if it really came down to it, they have the resources to pack up and find jobs in other cities or those who can pay higher electric bills when, as predicted, Miami has 84 days above $90^{\circ} \mathrm{F}$ degrees by 2050 ) ("Future Days Above $95^{\circ} \mathrm{F}^{\prime}$ ).

However, when Miamians, or Caribbean citizens, or anyone who lives in lowlying coastal areas or on small island states surveys the land adjacent to the ocean and then, retreating from the landscape, surveys environmental rhetorics and regulations and policies, they would do well to ask: What the fuck is this?

And they are. (Some of them, albeit, more politely).

The CLEO Institute (CLEO), a Miami nonprofit dedicated to climate change education, engagement, and advocacy, organized four town halls in underresourced neighborhoods across Miami. In each, citizens conveyed these primary concerns: 
Number 1: Emergency management: We don't want to be another New Orleans; who knows when the next Katrina will hit.

Number 2: Education: Why isn't anyone talking to us about this? Why isn't anybody teaching our kids this in their schools?

Number 3: Gentrification: We live in the highest areas - where are we supposed to go when king tides flood Miami Beach and they all start flocking over here?

Climate change is a threat multiplier - it intensifies existing problems and deepens instability. Across the globe, it will amplify the rate of species extinction, exacerbate food insecurity, increase health risks, reduce agricultural outputs, cripple infrastructure, slow down economic growth, produce more poverty traps, contribute to violent conflicts, and displace people (IPCC).

Despite the far-reaching social, health, economic, welfare, and equity issues that climate change will continue to worsen, large swaths of Americans see climate change as an environmental, scientific, or political issue, while fewer see it as a moral, poverty, social justice, or religious issue ("Climate Change in the American Mind"). When people think about climate change, they think about policies and laws, scientific studies and news briefings, polar bears and glaciers. They don't think about ordinary people and, often, they don't think about communities that will be impacted differently than they might. At a 2018 Climate Communications Symposium, Caroline Lewis, the founder of CLEO, said, "People aren't connecting the dots. It's our job to help them". 


\section{IMAGINED COMMUNITIES}

Miami, well, the current idea of Miami, glistens in the imagination - a warm, semi-exotic space that at once thrums with energy and languidly undulates through sultry rhythms. In the imagination, Miami is upstaged by its spectacular metonym, Miami Beach, a borrowed paradise, a barrier island of white sand beaches and dunes dredged up from the bay floor and molded into a tropical fantasy. A Google image search of Miami compiles a collage of turquoise waters framed by gleaming skyscrapers, neon lights burnishing the surface of the waves, palm trees fringing the landscape.

Venture out from that illusory island and you drift out of the tropics - several bridges connect it to Miami, the dense, sprawling city that has crept into the Everglades to the west; Miami is housed in Miami-Dade County, the seventh most populous county in the United States, cradled in the southeastern tip of Florida - and then back to them South Florida sits above the curved vertebrae of the Caribbean islands, the thousands of land fragments jutting out of the Caribbean Sea to form an archipelago - and then, you are awash in many places - the Caribbean rolls into the Gulf of Mexico, which laps into the bayous of Louisiana and Alabama, is barred by levies from flooding the bowl of New Orleans, and washes warmly onto the eastern shores of Mexico and Central America.

Colloquially, Miami may be an island, a city, a county, a region, or something very much less concrete than any of these. It is, at times shrunk to Miami Beach, can shrink even to the Atlantic-facing rim of that island - ignoring that we have a bay, which sometimes doesn't make it to the fictive blueprints - or magnified to represent South Florida or looped into a massive, hemispheric or transatlantic network. However, it has finite boundaries. Miami is not the Southern United States (Florida is popularly the only 
state where the further north you go, the further south you get). It is not Orlando, the seat of Central Florida. It is not Palm Beach, or Fort Lauderdale, some of the other major cities of South Florida, although the term Miami is at times deployed to refer to the regions in which those cities lie. And so while the word "Miami" does not refer to a stable, clearly defined place or a stable, clearly defined group of people, Miami is some place and some people because it is not other places and other people.

Miami is, like all places, an imagined community.

The term "imagined community" was coined by Benedict Anderson who, in tracing the origins, shifting meanings, and emotional potency of nationalism, argued that a nation is an abstract shared identity between people who are disparate and distant from one another. People in both Spokane and Santa Cruz feel a kinship, a shared "Americanness" with each other, though their lives are immeasurably different, though they have never met. Anderson observes that "regardless of the actual inequality and exploitation that may prevail in each, the nation is always conceived as a deep, horizontal comradeship" (Anderson 7). This is not to say that people feel equal in the eyes of their governments or their fellow citizens or that they are blind to inequities and exploitative systems. It is that often, though certainly not as Anderson suggests, always, despite these differences, people feel that shared nationality confers some kind of kinship.

If we have familial attachments to our countries, we are perhaps even more at home in our cities. On all my backpacking trips abroad, I have met fellow Americans. But on several trips, when I have mentioned I'm from Miami, someone's eyes have lit up excitedly, and I learn they are from Ft. Lauderdale or Palm Beach; recognizing shared or neighboring origins creates a bond. 
It is, after all, not only nations that are imagined communities: "All communities larger than primordial villages of face-to-face contact (and perhaps even these) are imagined" (Anderson 6). A similar inventiveness as that required for nationalism is required for regionalism or some kind of cityism. Consider that South Florida has six million residents, slightly less than the population of Lebanon or Nicaragua. Miami-Dade County accounts for almost half of that, with a population of 2.69 million, around the population of Jamaica or Qatar. The City of Miami has about 450,000 residents, similar to Guadeloupe or the Maldives. I will never meet most of the people I share my Miami identity with and though we are proximally connected, we will all live very different lives.

It is the idea of belonging to a Miami community, rather than an actual kinship, that makes it so moving to meet a fellow Miamian in a hostel in Lima or in Hanoi. In conversation, we build this community together, grasping for connections, question after question, constructing our shared Miami-ness no matter how little we actually share in common. "Did you ever go to Super Wheels when you were a kid?"; "Do you by any chance remember a Tatiana Gutierrez at Gables?”; “Where were you during Hurricane Andrew?" (The last is always a guaranteed relationship builder; everyone has an Andrew story).

However, though Miami is an imagined community, it is perhaps not one that offers the "deep, horizontal comradeship" of the kind of nationalism Anderson envisions, the kind of comradeship for which, he argues, people give their lives. No one in my social circle, admittedly limited, has ever profoundly declared their willingness to sacrifice themselves for the good of South Florida. In the imagined community a city 
offers then, we perhaps feel paradoxically both closer to and less bound to those around us.

The imagined communities we hold in our minds are shaped by our experiences and the stories we hear about the places we live. The evidence that feeds our communal concept is necessarily incomplete. Experiences we have not had, and stories we have not heard, are not imagined. Rob Nixon, using Anderson's model of imagined communities as a starting point, introduces the idea of "unimagined communities" in his study of environmental violence in the global South. He maintains that "narratives of national development are partial narratives that depend on energetically inculcated habits of imaginative limit that hide from view communities that inconvenience or disturb the implied trajectory of unitary national ascent" (150). Nixon speaks specifically about unimagined communities that are displaced - geographically, culturally, rhetorically - to make way for resource extraction or development, for example the construction of megadams, but his model has broader applications.

Rhetorical erasure is more easily accomplished when populations are halfway around the globe or in less densely populated spaces, but it is also at work in our cities. The idea of Miami is a partial narrative that hides from view communities that testify to the fact that Miami is, for example, not simply a place of wealth, but a place of wealth disparity. Miami is highly segregated and sprawls across a large area. Narratives about Miami and experiences of Miami are constructed in and about neighborhoods, but these stories have difficulty crossing the social and discursive membranes that separate those neighborhoods. And so, some citizens of Coral Gables are unaware of the Miami that the citizens of Goulds know. While people in Brickell and Key Biscayne or other affluent or 
middle-class neighborhoods were scrambling to buy hurricane supplies and plywood for Hurricane Irma, other people in Miami were staring at empty bank accounts and wishing they had the luxury of scrambling for supplies. However, conversations and news were largely silent here, instead churning out story after story of the totalizing frenzy of hurricane preparedness.

These are only some of the variable, competing visions of Miami. Miami is chimeric, in both the imaginative and genetic sense of the word. However, all the Miami's that are conjured up, all the Miami's that are inhabited day-to-day, are united in shared vulnerability. Miami is one of the places most threatened by climate change - it has low elevation, sits on porous limestone, and has a high urban density. It faces risks of climate change, including salt water intrusion, increased intense weather events, higher temperatures, drought and flooding, sea level rise, health risks, climate gentrification, and climate-induced forced migration, among others.

However, it is imperative to stress that though all Miamians are vulnerable in the face of climate change, they are stratified into communities that will bear the consequences of that threat with different intensities. This is the crux of climate justice; some will be hit harder than others, and often, those frontline communities who are hit the hardest are those who have contributed the least to the problem. Most pointedly, there are differences in physical vulnerability. Consider that "many exposed assets are owned by wealthy investors, but poor residents are less able to prepare for climate impacts and respond to disasters like flooding when they inevitably arrive... Some of the most vulnerable communities are on the western, inland side of Miami Dade County and receive less attention than coastal cities like Miami Beach (Treuer 9). In addition, 
Miamians are stratified by access to information about climate change and sea level rise, access to policy-making, and methods of risk-assessment. This difference is compounded by the multitudinous relationships that people have to nature and their environments.

Miami could be envisioned as a cohesive community united by shared vulnerability in the face of climate change. It is, simultaneously, composed of substrate communities, including frontline communities that are often politically and discursively unimagined. How we imagine Miami, and how we imagine ourselves within it, how we imagine the we involved in this imagining, will delimit how we can respond to climate change. 


\section{IMAGINING A LIVEABLE WORLD}

Imagination magnifies our capacity for survival. (I say "our” purposefully; the lone hero will not be striding out of this apocalypse). We must, of course, physically survive, in some fashion or another, when the seas inevitably rise. We need clean air and water, housing and transportation options, protection from extreme weather events. Survival is, however, more than physical. Thomas Berry defines survival as "survival in the human mode of being, survival and development into intelligent, affectionate, imaginative persons thoroughly enjoying the universe about us, living in profound communion with one another and with some significant capacities to express ourselves in literature and creative arts" (37). It is this survival, a relational, imaginative, communal survival, that we must also build.

Ursula K Le Guin, the celebrated sci-fi and fantasy writer, underscored the vitality of imagination in an essay titled "Why Are Americans Afraid of Dragons?" In this defense of fantasy and fiction, she laments a culture of disenchantment, which she specifically links to a hyper-competitive, materialistic society or, in other words, a world where yachts matter but hobbits don't. We are, I think, less afraid of dragons now than when she wrote it - the world had yet to see people lining up at bookstores during witching hours for the next Harry Potter release, or Halloween parties thronged with Khaleesis and Drogos. But her defense is still applicable, because for Le Guin, imagination is not quarantined to riveting hours in front of the television. She advocates for an imaginative life.

Le Guin defines imagination as "the free play of the mind, both intellectual and sensory." Imaginative projects of any scale, from solutions to sea level rise to daydreams 
during the morning commute, are more than images we project to our inner selves. Imagination happens in the mind, but if we chuck the outdated mind-body split and affirm our mind-body connection, imagination is not just a cerebral exercise - our senses are engaged and, I would add, so are our emotions. Imagination is a vibrant human experience, a ludic delight. To this point, she wryly writes, "I doubt that the imagination can be suppressed. If you truly eradicated it in a child, he would grow up to be an eggplant." Imagination, she says, is coterminous with being; to be $i$ s to imagine.

We are all imaginative people. The phrase "free play of the mind" might evoke images of untrammeled flights of wonder of the sort only found in children or in the decidedly mad, but that is a conflation of imagination and hallucination. Even our most bizarre fictions - Alice's Adventures in Wonderland, Hitchhiker's Guide to the Galaxy, the interdimensional television episodes of Rick and Morty - were not hallucinated into being (At least, not entirely. There may have been some hallucinations involved; looking at you Lewis Carroll). Imagination can be channeled purposefully. "To be free, after all," Le Guin reminds us, "is not to be undisciplined". She emphasizes that "the discipline of the imagination may in fact be the essential method or technique of both art and science." Disciplined or undisciplined, imagining seems sometimes like an individual action. Imagination gestures towards a kind of solipsism - what exists in my mind (present before me or not) is what there is. Or imagination and vision might exist seemingly in tautology: imagination broadens or narrows what we are able to see and what we are able to see broadens or narrows what we are able to imagine. If that were the case though, there would have never been hobbits or dragons, or for that matter, democracies. 
Imaginations can be, and must be, leveraged collectively and publically. Jedidiah Purdy, a professor of Law at Duke University, identifies imagination as one of the bulwarks of democracy: "Imagination means how we see and how we learn to see, how we suppose the world works, how we suppose that it matters, and what we feel we have at stake in it" (6-7). Purdy also affirms the importance of imagination, asserting that "It should be clear that, far from being frivolous make-believe, imagination is intensely practical," partially because it "enables us to do things together politically: a new way of seeing the world can be a new way of valuing it" (7). Additionally, new ways of valuing the world germinate new ways of acting within it.

During the Civil Rights movement, for example, citizens harnessed their imaginative faculties to gain agency in systems that were stacked against them, including educational systems. Limited access to literacy education was leveraged as a gatekeeping tool to deny suffrage (via literacy tests) and prevent upward mobility. People had to promote and create opportunities for literacy education outside of traditional schooling. These citizens, who were legally and culturally excluded from first-class citizenship and formal educational institutions, established collectives, like the Freedom Schools and Citizenship schools, that taught practical literacy.

Paul Feigenbaum, a professor at Florida International University, calls these acts of collaborative imagination: "Collaborative imagination emerges from the premise that earning activism requires people to cultivate expansive and diversified capacities to imagine alternative worlds - more just, more tolerant, more compassionate, more sustainable - from that which exists in the present and then to employ mutually derived, rigorous methods for realizing those worlds" (6). Collaborative imagination is a slow, 
democratic process that requires "melding utopian thinking with practical action" (Feigenbaum 2).

Our contemporary struggles for a more just, sustainable world require collaborative imagination. Climate change, when you look at the science, is overwhelming and grim. Without utopian thinking, it can be crushing. (Let's be real; even with utopian thinking it can be crushing). That utopian thinking rubs up against pragmatic concerns - how to work with recalcitrant elected officials, how to scale down solutions that are beyond local budgets, how to balance short-term solutions and longterm solutions, how to make sure everyone gets a seat, or a voice, at the decision-making table. Navigating between the ideal and the actionable requires a supple, and resilient, set of imaginations working jointly through pragmatic obstacles to build an alternative future that is responsive to the needs of different stakeholders and that does not unimagine communities from that future world. 


\section{BARRIERS TO SEEING}

This imagination is difficult, wickedly complicated work. Even for Miamians who are well aware of the disasters and inequities posed by climate change, there are many barriers to seeing the issues and collaborating with others to bring about change. Addressing climate threats requires, among others, the difficult tasks of identifying the connections between seemingly disparate issues, balancing global and local differences, orienting oneself simultaneously towards current and future problems, working with different stakeholders with competing goals, finding the right rhetorical and emotional strategies to onboard people, navigating between ideals and actions, and cultivating empathy for those across the globe, in our communities, and those yet to be born,

\section{Nature vs. Culture}

Somewhat counterintuitively, the concept of nature is a hurdle for building a broad consensus around climate justice. Nature is an edenic, natural world. We find nature when we hike seven hours up the jungled slopes of a dormant volcano and pause at the top, ensconced in the humid stillness, to marvel at the reflection of the world in its crater lake. In the United States, the word "nature" might conjure up several images: native people living on the land, settlers pushing west, transcendentalists roaming through woods, hikers trailblazing through hills and mountains, canoes drifting across lakes. In these tableaux, nature is outside of and beyond the human. It exists in the nostalgic past and in the small, immaculate pockets kept unspoilt by stalwart environmentalists and government protection. People interact with it, travel through it, escape to it, but they are apart from it. 
Nature doesn't just exist out there though, strewn with treasured experiences of sublimity and beauty. Jedediah Purdy suggests that the modern feeling of interacting with the environment is that of the uncanny, rather than the beautiful or sublime. It is a dizzying and disquieting unease, a loss. "Uncanniness," he writes, "expresses an uncertainty at the heart of the Anthropocene" (243). It has become increasingly clear that nature and culture are not separate, and that nature means only what we want it to mean: "Uncanniness is a reminder that these meanings are partly human things, not simple readings of an indwelling mind in nature, that we are not sure what, if anything, is looking back at us" (243).

The idea of nature is problematic because it creates partitions where there are none by quarantining the average citizen from the natural world instead of encouraging understandings of the relationships between all human and nonhuman subjects. The word environment does better here - it suggests a place that we have strong relationships with, that we are reciprocally dependent on. Environments are not just marshes and fields and desert; look outside your apartment window at the urban sprawl and you gaze upon your environment. Even still, there can persist a division - the environment doesn't really creep into our cubicles and kitchens. It's a backdrop that we layer civilization over.

Unlike environments, ecosystems are networked; they foreground relationships. Reinvisioning natural environments as nodes in broader ecosystems in which all peoples, places, and processes are related rather than as insulated, pristine, natural spaces allows for discourse about urban ecologies, climate gentrification, and the local politics of climate change alongside discussions of species extinction, wilderness preservation, and other concerns of environmentalism. The concept of ecosystems collapses the boundaries 
between nature and culture, between urban and rural, between local and global and knots these all together.

\section{Global vs. Local}

One of the challenges of environmental movements, though, is how to present globality without effacing the very real divisions that exist between populations and places. The world is not homogenous, but imagining one large exalted "Blue Planet" can make it seem that way. Throughout the $20^{\text {th }}$ century, modernization and globalization heightened global conceptions of the environment. In the 1970s, for example, the interconnectedness of the world was given an image for the first time - a photo, taken in space, of the Earth, suspended in space. Ursula Heise observes that these images, which, ironically, had technical and military origins, were co-opted by the environmentalist movement and displayed at the first Earth Day in 1970 (22). These images helped to catalyze environmental movements that relied on the ideas of the Blue Planet or Spaceship Earth to encourage awareness of relationality and cultivate responsibility for the planet.

These photos were perhaps meant to reproduce the overview effect, a cognitive shift succeeding the awesome experience of seeing the planet from space that awakens an appreciation of the fragility and wonderfulness and interconnectedness of life sustained in the void. Astronaut Ron Garan describes his experience gazing upon Earth as a moment of intense ambivalence:

"I was hit in the gut with an undeniable, sobering contradiction. In spite of the overwhelming beauty of this scene, serious inequity exists on the apparent paradise we have been given. I couldn't help thinking of the nearly one billion 
people who don't have clean water to drink, the countless number who go to bed hungry every night, the social injustice, conflicts, and poverty that remain pervasive across the planet."

The Blue Planet approach doesn't always translate into this kind of clarity, however. At the same time that it foregrounds the connectedness of all things, it sometimes obviates distinctions, and creates one large imagined community at the expense of articulating the distinct characteristics and needs of many communities. Privileging the global over the local or the local over the global precludes the dynamic interactions between and within these systems - we are left with myopic or hyperopic understandings of the world.

\section{Present vs. Future}

Another barrier is that climate threats are a type of slow violence, one that "occurs gradually and out of sight, a violence of delayed destruction that is dispersed across time and space, an attritional violence that is typically not viewed as violence at all" (Nixon). When assessing risk, people focus on the near and present: "One of the most robust risk perception findings is that people are deeply myopic and steeply discount or tend to avoid distant future risks" (Treuer 30). People have what Patricia Linville and Gregory Fischer call a "finite pool of worry": a controlled, confined capacity for worrying about problems (qtd. In Marshall 78). Slow violences, for many reasons, are not granted access to that pool.

At national and international levels, governments are trying to put out fires in the here and now. In ordinary, domestic lives, there are rents to pay, elderly relatives to take care of, jobs to find or keep, children's schooling to support, groceries to buy, and a thousand other daily stressors. People are aware that the environment is in distress, but 
they experience this awareness differently. There are, just to speak of our own country, those who drink out of Flint's taps and fish out of the Gulf's oil-slicked waters and those who read about them or watch news footage.

For some, the awareness is embodied - they breathe the pollution, the knowledge sits in their lungs. For others, the awareness is vague, amorphous, punctuated every so often by the disasters that make it to the news, but generally kept buoyant by key ideas: we have an increase in pollution, and a decrease in natural spaces; we have an increase in people, and a decrease in resources; we have an increase in temperature, and a decrease in hospitable living spaces. However, these are internalized as unfortunate but immitigable facts rather than acts of violence that need to be addressed.

Slow violences are further obfuscated by a culture of frenetic and amnesic media consumption, buried under a deluge of Instagram posts, Facebook feeds, Snaps, tweets, podcasts, nightly news, morning radio, newsletters, newspapers, magazines, email, text messages, and even the occasional voicemail or book. "How can we," Nixon asks, "convert into image and narrative the disasters that are slow-moving and long in the making, disasters that are anonymous and that star nobody, disasters that are attritional and of indifferent interest to the sensation-driven technologies of the image world?" (3).

The society Nixon conjures is that outlined by French Marxist Theorist Guy Debord in his 1967 indictment of mass production and consumption, The Society of the Spectacle. Debord asserts that modern consumer societies are presented as "an immense accumulation of spectacles" that replace direct experiences with facsimiles of experiences. Debord explains that "the spectacle is not a collection of images; rather, it is a social relationship between people that is mediated by images". The "sensation-driven 
technologies" - for us in 2018, our vast social media networks, media channels, and communications systems - are not the spectacle themselves. The culture that accrues around and through these technologies becomes the spectacle.

A spectacular society is not a totally Huxlean one, in which contemptible, pitiable, people give themselves over to vacuous, insipid indulgences. It is, instead, one in which time is refracted into discrete units, quickly forgotten, subsumed into the miasma of yesterday's headlines and scandals. There are simply masses of information - much of it crucially important - that are difficult to wade through and prioritize. Nixon urges that all violence, but "above all, environmental violence, needs to be seen - and deeply considered - as a contest not only over space, or bodies, or labor, or resources, but also over time" (8). This temporal contest is not simply one between things that matter (climate justice) and things that don't (reality television). It is often a contest between things that matter (climate justice) and things that matter (refugee crises).

\section{Science vs. Profits}

However, the imperceptibility of slow violences is not just the accidental byproduct of a spectacular society. There are neoliberal agendas that withhold or mask climate science and discourse - oil, gas, and other industries have oozed millions of dollars into fighting climate and energy reform. Robert Brulle, an environmental sociologist and professor at Drexel University, conducted the first peer-reviewed academic study of the mobilization of financial resources by the climate change countermovement (CCCM). The final sample for his study consisted of " 140 foundations making 5,299 grants totaling \$558 million to 91 organizations” between 2003 and 2010. He found that the "91 CCCM organizations had a total income of more than $\$ 7$ billion over 
the eight year period 2003-2010, with an annual average income exceeding $\$ 900$ million" but also noted that "since the majority of the organizations are multiple focus organizations, not all of this income was devoted to climate change activities." Nevertheless, this foray into tracing dark money allowed him to definitively conclude that the CCM involves "a large number of organizations, including conservative think tanks, advocacy groups, trade associations and conservative foundations, with strong links to sympathetic media outlets and conservative politicians."

As such, the repression of information is also alive and well in government institutions. The Sabin Center for Climate Change Law at Columbia Law School and the Climate Science Legal Defense Fund have partnered up to record reports of U.S. government climate science silencing since the November 2016 election (They aim to expand their reporting to state level silencing in the future). At the time of this writing, they have documented 96 instances of silencing. The Silencing Science Tracker defines silencing as "any action that has the effect of restricting or prohibiting scientific research, education or discussion, or the publication or use of scientific information." Silencing acts are organized into six categories - government censorship, self-censorship, budget cuts, personnel changes, research hindrance, and bias and misrepresentation. As an example, the most recent incidence of silencing involves a report from the National Parks Service, which was edited to remove the term "anthropogenic" climate change whenever it appeared and remove references to "human activities" that cause climate change.

It would be tempting to suggest that silencing is always a malicious, greedy, or ignorant act, that only rapacity fuels the silence surrounding, for example, a sinking Miami, but that is overly simplistic. Consider that Miami's economic engine is powered 
by the idyllic vision of Miami, the one keeps tourists flocking down, developers eager to build, investors keen on sinking in money. Jeff Goodell provides a balanced discussion of this dilemma in The Water Will Come. Goodell reflects on conversation he had with Henry Briceño, a geologist at FIU who organized studies to test floodwaters on Miami Beach. Those studies revealed that flood sites had fecal levels alarmingly above (at one site 630 times as much as) the legal limit. Briceño acknowledged why the news about floodwaters, and the fact that those floodwaters were being pumped into the bay, was not widely welcomed: "The entire tourist economy depends on the quality of water here. The economy needs to be somehow protected. I understand that." (245). He also, however, noted that economic protection was being secured at the expense of human welfare. "I also understand," he said, "that because of sea-level rise, everyone here, sooner or later, is going to have to move away. In the meantime, we need to have the best standard of living we can..." (245).

Personal wealth is, of course, also at stake on Miami's coastlines. Goodell also recounts a conversation he had with Jorge Perez, well-known Miami real-estate developer and billionaire, in which Perez routinely asserted that he did not much discuss or consider climate change, an assertion Goodell found hard to believe in 2016 when discussions about climate change were everywhere. However, "It was very possible to imagine, as a Miami architect who has worked with Perez suggested to me, that Perez was afraid that if he talked about sea-level rise or acknowledged the risk, it would call into question some of his waterfront projects and, ultimately, cost him money" (93). 


\section{Hope vs. Dread}

When people actually talk to people about all of these issues, they sometimes talk to them in ways that make it difficult for their audiences to emotionally engage. Somewhat counterintuitively, motivating people through a love of the natural word or through fear of disaster may not be effective communication strategies.

Pieces that gush about nature and preserving biodiversity try to motivate people through a love of the natural world and hope for a more verdant future. This approach may fail to illustrate the relationships people have with their own environments. These rhapsodies often portray the environment as a site for sublime individual experiences, not collective action. For urban populations who don't have memories of escaping to summer camp or hiking in the mountains, these rhetorics fall especially flat.

Terrifying people isn't the way to go either. Rachel Carson was able to capitalize on Cold War apocalyptic anxieties to frighten her audience into caring about pesticide use. However, this is no longer Rachel Carson's Cold War era, when DDT was as pernicious and alarming as the potential radiation that might sift through the air and blanket the earth. These days, apocalyptic narratives don't go a long way towards generative ideation. People are somewhat used to the idea of a doomed world.

People have always lived side-by-side with terrors: we live in a world of earthquakes, tsunamis, hurricanes, wildfires, famine and drought. We now also live in a world of nuclear armament, wealth disparity, terrorism, political upheaval, corporate greed. Our fear has settled into a permanent disquietude, the feeling of responsibility for the current state of affairs mellowed to a resignation that the world does not often allow for the concurrence of communal activism and individual success. Climate justice 
frameworks must adjust to a generation that is inured to risk and disparity. Thomas Berry, a religious scholar and professor who reflected on the religious character of environmental crises, pronounced that "millennial expectations are reduced to endurance in a desolated natural world" (31). Ursula Heise, a professor of English at UCLA and a faculty member of UCLA's Institute of the Environment and Sustainability, offers a similar assertion: "People no longer fear environmental disasters in the future so much as they "dwell in crisis," as he [Frederick Buell] puts it: that is, "they live with an awareness that certain limits in the exploitation of nature have already been exceeded, that past warnings were not heeded, and that slowly evolving risk scenarios surround them on a daily basis" (142).

People still feel anxiety, dread, or confusion though. Those feelings don't provide the kind of exigency that climate action requires, but they are feelings that need to be addressed. Paraphrasing Renee Lertzman, visiting psychology fellow at the University of Portland, George Marshall asserts that "people need to be in the place where their anxieties are recognized, to be able to say, "Yes, this is scary; this is hard," and only then, she says, can we be truly mature, creative, strategic, and innovative" (204).

Citizens and experts feel a lot of things about climate change: love and hope, dread and despair, and all the emotions in between (sometimes, in the same day). Rhetorical practices that leave out the emotional messiness of climate action (by sticking to entirely hopeful or apocalyptic messages, or by avoiding emotion altogether) are disengaging. 


\section{Ideals vs. Actions}

One of the emotionally messy areas that needs to be addressed is the tension between ideals and actions. The image of the environmentalist that produces only a thimble's full of waste a year, sustains themselves wholly through their personal organic vegetable garden, and pedals cheerfully to work is optimistic, but alienating. Firstly, it prevents people from talking about the truth. George Marshall, for example, points out that climate change scientists and climate justice advocates rarely discuss the conflict between their professional aspirations and the fact that their jobs require a lot of flying (or that they even simply enjoy travelling by plane), which makes them complicit in a lot of carbon pollution.

I'm not exempt from this. I drive to work each morning, a journey of a mile, in my 2000 Honda Civic (the gas cap of which I lost for several months, compounding my carbon footprint) and preach about Miami's fragile ecosystem. I tell myself: I arrive at work early, often when it is dark. The roads in Miami are not friendly to bikers (which is true - biking in Miami can be a fatal activity). These are stories I tell to bridge the gap between my values and my actions. These stories are not invalid, nor do they exempt me from responsibility. But not talking about them isolates me from people who are caught in the same struggle and makes it easier for me to pack them quietly away.

Because contradictions between ideals and actions are glossed over, people feel that they are up against unachievable standards. Paul Feigenbaum calls these idealized images the progressive perfect standard and writes that "these manifestations of the perfect standard deter people from trying on activism for size: starting humbly and making mistakes as part of a learning process, finding allies and gradually coming to 
understand the broader complexity of the issues" (Feigenbaum 54). Progressive perfect standards encourage all-or-nothing approaches where people are intolerant of imperfections in their own approaches and in others'. 


\section{A PEOPLE'S CLIMATE MARCH}

Act of disciplined, collaborative imagination are required to bypass these barriers. Communities, both imagined and unimagined, can be reimagined by subverting the institutions that control those narratives (WHICH) and clamoring for political transparency and communal visibility. These resistances should ideally exemplify "the very values for which those communities struggle" (Butler, Notes 67). In other words, a movement that aims to create a more equitable community must conduct its resistance equitably by creating kinship networks across community lines and diversifying the voices that have access to decision-making.

The People's Climate March (PCM) is one such act of disciplined imagination. The march was first organized in New York in 2014; the original PCM was the largest climate change demonstration in history to date and it reframed conversations about climate change by foregrounding climate justice, promoting community, and asserting the criticality of networks between frontline communities, scientists, and other stakeholders. As the name emphasizes, the march put people at the front and center of climate issues. It was not the environmentalist movement of the white, upper middle class. Instead, "people of color, low-income people, and indigenous peoples - those historically isolated from the mainstream climate movement—literally led the march" (Young 10).

Lisa Young documents the historical evolution of the climate movement, as it culminated in the PCM. Particularly, she focuses on the collaboration of climate action groups (concerned with fossil fuels and carbon emissions) and climate justice groups (concerned with racism, classism, colonialism and neoliberalism) that had previously long been split by the vulnerabilities they sought to address (11). Vulnerability to climate 
change, according to the IPCC, is "the degree to which geophysical, biological and socioeconomic systems are susceptible to, and unable to cope with, adverse impacts of climate change." Climate action groups historically focused on geophysical and biological impacts. Climate justice groups emphasized socio-economic impacts and furthermore identified the particular sources of injustice that magnified those socio-economic impacts. These groups understood that, as Judith Butler says, vulnerability is also "a deliberate exposure to power" and that systems of power had been built so that different groups were more vulnerable and, to put it bluntly, more likely to die than others ("Rethinking" 22).

The PCM planning team consisted of "well-resourced national groups with a tradition of building mass movements to lobby Washington, led primarily by white organizers" and "poorly-resourced local groups fighting for environmental justice in their communities, led primarily by organizers of color" (55). Young writes that the atmosphere was "rife with discomfort and distrust" (55). However, the organizers were committed to building a broad coalition and expanding the visibility of all groups speaking out about climate change. The steering committee that eventually formed represented an array of interests - climate action, climate justice, labor groups, interfaith groups, and online organizers. (57). These groups jointly developed a collaborative framework for equitable decision-making processes which, while it by no means removed all tension or conflict, allowed for trust and relationships to build between these disparate groups.

In 2014 and in the succeeding years in which the PCM was held, satellite marches and events were held across the country and across the world. In 2014, in Miami a group 
of 100-200 people demonstrated in solidarity with the March in New York. In 2015, the Miami Climate Alliance (MCA) was formed to organize the Miami People's Climate March, a local arm of the New York march. An estimated 1,200 - 1,500 people marched from Stephen P. Clark Government Center in Downtown Miami to the Torch of Freedom. The MCA organized a Miami People's Climate Rally in 2016 and another PCM in 2017, which began with a rally at Jose Marti Park in Little Havana and continued with a march through Downtown Miami to the historic Overtown Lyric Theater.

Like the original PCM, the marches and events in Miami brought together people from different backgrounds - over 100 community leaders, students, staff of social justice organizations, environmentalists, scientists, teachers, and climate activists ("Mission"). Like the original PCM, the Miami events connected the dots between environmental and social concerns. For example, the flyer from the 2017 march enjoined people to march for "Jobs, Justice, and Climate", explicitly linking these issues together. And like the original PCM, the Miami events voiced a communal demand for climate justice through individual expressions on a range of issues.

Speeding through the history of the PCM glosses over the conflicts and tensions that occurred. The marches, the events, their organizing, and their outcomes weren't flawless, and the struggles and shortcomings of the events are beyond the scope of this analysis. By addressing the successes, I don't wish to sweep these issues under the rug, but rather to acknowledge that in spite of the issues, the movements resulted in enormous strides for the climate movement.

By marching, citizens in unimagined communities demanded visibility for themselves, for their communities, and for their futures. They, quite literally, interrupted 
the landscapes of their cities and turned them into a complex ecosystem of people asserting their existence and their rights. Any public assembly, Judith Butler argues, is a "form of political performativity that puts livable life at the forefront of politics" (Notes 18). Bodies that assemble on the street or in other public places, including virtual spaces, create a "bodily demand for a more livable set of economic, social, and political conditions" (11). The PCM crafted a clear narrative about which bodies were making demands and which lives were under threat from climate change. In both the original PCM and the Miami events, frontline communities were given the most visibility. The 2017 Miami PCM included performances by Latinx, Indigenous, Afro-Caribbean, and African artists, dancers, and musicians at the pre-march rally in Jose Marti Park while Afro Caribbean performers and drummers led the march itself

Assembling bodies in the street creates a shape for the amorphous and eventual threat of climate change; a spectacular culture needs a spectacle to make slow violence visible. Rob Nixon contends that confronting slow violence requires giving "figurative shape to formless threats whose fatal repercussions are dispersed across space and time" and coming up with "iconic symbols that embody amorphous calamities" and "narrative forms that infuse these symbols with dramatic urgency" (10). Streets in Miami are generally filled with traffic and we don't see a lot of pedestrian traffic. To see these spaces teeming with a force of unified, purposeful people is visually arresting.

By disturbing routines, a march retrieves climate threats out of the future and injects them into the present; it elevates climate threats from the white noise of the background to the level of urgent and imminent danger. Marchers give mass and number to the people, the actual lives and faces and bodies, that climate change already affects 
and will continue to affect. Organizers and participants ensure that, beyond the sheer volume of participants, the march is spectacular in other ways as well. Signs, props, and costumes translate vague threats into clear issues. In the 2017 Miami PCM, the Urban Paradise Guild constructed a 45 foot long snake that moonlighted as a symbolic representation of the Sabal Trail Pipeline, a natural gas pipeline from Alabama to Florida. The snake, carried on poles by a team of volunteers, was jet black and capped by an enormous fanged snake head, signifying the poisonous blow that the pipeline would strike to the environment and communities along its path.

The issues the PCM brought to attention were a blend of local and global concerns, or a glocal understanding of climate change. Roland Robertson argues that the distinction between global and local as purely oppositional terms disregards that locality is "an aspect of globalization" and offers the idea of glocality as a bridge (30). Glocalization means that global ideas or products can be tailored for local markets and also that local markets can influence global concerns. Each march or event highlighted the fact that though we all share the same planet, we do not share equally in vulnerability and we are not all vulnerable in the same ways.

Climate change is an undeniably global issue - carbon is trapped in the same oceans, temperatures are warmed across the planet, sea level rise occurs across the globe, intense weather events worsen. However, the experience of these universal changes differs from location to location. For example, the sea does not rise uniformly in all locations; some sites will experience higher levels of sea-level rise than others. Miami's porous limestone base differentiates it from other locations where seawalls can keep out the encroaching ocean. Our mosquito population, lovingly nurtured by our subtropical 
climate, will increase as breeding seasons extend with the warming climate. We can expect larger, more powerful, and more frequent hurricanes. While the central message of the PCM - climate justice - was embraced in Miami and across all the satellite events, that message was tailored to each of them. Just as importantly, those satellite events influenced the global message of climate justice by asserting their local concerns.

The signage of the marches provided a visible representation of the interconnectedness of different issues, both across and within different communities. At the 2017 Miami PCM, the leading banner starkly proclaimed, "We Resist". That expression of resistance was extended to all of the participants, who exercised their resistance individually and in solidarity with one another. Signs ranged from expressly environmental sentiments and declarations, "Love Your Mother" and "Water is Life", to broad affirmations, "Standing Up For Justice and Equality", to expressly political demands, "Protect Immigrants". Some signs identified key global issues, "Less Meat = Less Heat" while others articulated local concerns, "Don’t Gentrify Little Haiti”.

Signs also represented a range of emotional responses. Some promised dire consequences, "Act Now or Swim Later" and "There is no Plan(et) B", while others offered hopeful messages, "Rise Up Florida" and "I March For You + Me." There were signs disparaging Trump and admonishing the supporters of Big Oil - "Don't be Fossil Fools". And, as is the case at many marches, some participants injected levity into grave issues. A few marchers wore fish heads and carried signs that read "Fish Will Rule" and "Miami, Where Your Condo Is My Condo". One sign simply said, "Tengo Calor, Coño". (I would also be remiss if I failed to mention a charming Pomeranian wearing a sandwich board reading, "Bark If You Believe in Climate Change"). 
The mélange of messages, participants and ideas could be read as disorganized and disintegrative. Young observes that after the initial PCM, "much criticism was focused on the lack of a single powerful message" (61). However, she counters, "the march didn't lack a powerful demand. It just had more than one, and they were brought forth by The People, themselves, not some committee at the "head" of the PCM" (61). Young further explains, "by making explicit the fact that indigenous peoples, working people, students, environmentalists, anti-capitalists, peace activists, clergy, and scientists were marching in the same march, and by narrating their separate but integral roles in the climate movement, the lineup emphasized and established solidarity as a principle for the movement" (60). 


\section{LIVING IN RELATION; CLAMORING FOR OPACITY}

Wayfaring through the tangles of the Anthropocene and connecting the dots, as Caroline Lewis says, requires more than the pragmatism needed to organize a march. It requires an ethical roadmap that values difference, as the PCM did, rather than avoiding it.

I was at the symposium when Lewis spoke, and I scribbled her words down in my copy of Poetics of Relation by Eduoard Glissant, the Martiniquan writer, poet, and philosopher. (Packing my bag for the symposium, I cheerfully tucked in book, snacks, and water, ignoring the need for a notebook). The book is a gorgeous and groundbreaking exploration of Caribbean culture and identity in which Glissant introduces the Poetics of Relation, "in which each and every identity is extended through a relationship with the Other" (11).

This is not empathy. Empathy is, strictly speaking, impossible. We cannot know and feel as others do. But what we call empathy is not the knowing itself; it is a will to know, a desire to travel as far as possible towards the unachievable and the unknowable. What we call empathy is one experience of Relation.

Relation, however, is also knowing what we can't know. In the Western world, Glissant argues, Otherness is either annihilated or assimilated (49). People who are radically different are dehumanized, annihilated from our mental categories of personhood (and sometimes, in the case of genocide, colonization, and other brutal projects, then physically annihilated as well). Or people are subsumed into the only schema we know for making sense of the world - our own. We cannot understand others' interior complexity, so we mold it and mush it and stretch it until it more or less 
resembles ours. Once people have been neatly assimilated into our experience of personhood, then, narcissists that we are, we are able to care about them. Trying to suppress or control difference in this way, according to Glissant, is barbarism.

In Relation, Otherness is neither annihilated or assimilated. Relation is only made possible by the fact that others, human and nonhuman, are opaque or unknowable to us and by the fact that we are sometimes even opaque to ourselves. Glissant, in the Manthia Diawara documentary, One World in Relation, explains this idea:

"Everyone likes broccoli, but I hate it. But do I know why? Not at all. I accept my opacity on that level. Why wouldn't I accept it on other levels? Why wouldn't I accept the Other's opacity? Why must I absolutely understand the Other in order to live next to him and work with him? That's one of the laws of Relation. In Relation, elements don't blend just like that, don't lose themselves just like that. Each element can keep its - I won't say just its autonomy but also its essential quality, even as it accustoms itself to the essential qualities and differences of others".

If all of this seems rather ineffable and indefinable, that's because it is. (Relation is all the illimitable relationships and interactions and verbs and connections in the world, never static, always more than the sum of their parts. And even if we ignore it, Relation is still there). Glissant says as much. Relation cannot be proved, he says. It can only be imagined (174).

We approach Relation obliquely, like we approach a poem or any work of art. A poem is not a crystallization of thought. We sometimes speak of the facets of a text, like we can turn it to the light and count its multitudes as they take turns gleaming. Or we 
speak of layers, like we can roll our sleeves back and dig through the strata to unearth all its meanings. But we know that these metaphors don't quite fit. Art moves in and through us. There is something larger that swells around what we can define and what we can pronounce. It is exactly that something that enthralls us and moves us, though we cannot understand it, though by the time we finish explaining it we have reduced it to something more impoverished than it actually is.

Art is never fully transparent to me, but it resonates with me. When I visited the Art Institute of Chicago, I stood transfixed before Marc Chagall's America Windows, bathed in the brilliant cobalt light of the six stained glass panels, awed and exhilarated and overwhelmed. I felt like I was, as Galway Kinell says in his poem "Still Time", suspended in that bit of changed air between the palms of an ended prayer that "goes free to become the glitter on some common thing that inexplicably shines". Eventually, I moved to read the placard next to the panels and learned that they each symbolized a different facet American art and liberty, that the six panels evoked painting, dance, music, theater, literature, and democracy. Learning this enriched, but did not demystify, my experience.

In the same way that art is meaningful through its opacity, solidarity doesn't depend on sameness; it relies on difference. Opacity, Glissant says, would "bring us together forever and make us permanently distinctive" (194). We can't ever fully grasp other people, even the people we love most. Love exists not in spite of this opacity, but because of it. When we love people, we do not only love the parts of them that we understand. We extend our love to all of them. So I don't have to grasp other people in order to care about them, be interested in them, build towards goals with them, march 
with them. I don't have to like treefrogs, or bananas, or coral reefs in order to think they're worth saving and to recognize our interdependence. Glissant exclaims that we must "clamor for the right to opacity for everyone" (194).

Within a Poetics of Relation, difference, rather than being divisive, is empowering; this counters the tendency to glorify individuality and independence, to exalt those who pulled themselves up by their bootstraps in the rags to riches saga of the American Dream. Jenny Rice contends that "sustainable futures demand a strong ability to think about ourselves as beings who exist in multiple, asymmetrical networks" (43). Our ideas of selfhood, or individuality, don't exist in a vacuum - they are influenced by the various, and sometime competing, networks that we inhabit. The asymmetry, or conflicting nature, of these networks makes it possible for someone to be, for example, both a lover of flying and a staunch environmentalist. Rice also argues that "public subjects", people who inhabit various roles when they speak and act on issues that put them into relation with others, "are never single" (43-45). We are born into a world already thick with other people, other beings, other ideas.

We understand ourselves in relation to the things that are not-ourselves, in the same way that we define Miami by the places and people that are not-Miami. Independence, when looked at this way, is literally nonsensical; we can only make sense of ourselves in relation to others. Butler posits that "it is not just that this or that body is bound up in a network of relations, but that the body, despite its clear boundaries, or perhaps precisely by virtue of those very boundaries, is defined by the relations that makes its own life and action possible" ("Rethinking" 16). Individuality still exists. At a very physical level, my body is an individual organism separate from other organisms. 
But individuality is not independence - it is being separate from and with others. And beyond being vaguely with others, we are concretely dependent on them. If we, as Butler encourages us to, theorize the human body as having a certain dependency on the ecosystems it exists in, "the human itself proves to not to be divided from the animal or from the technical world" ("Rethinking" 21). Because physical, social, and emotional needs tie us to both humans and nonhumans, we cannot discuss individual needs as separate from social or communal needs.

Understanding relationality in this way is not only ethical; it is intensely practical. The ethics of Relation has a corollary in systems thinking. A system is an "interconnected set of elements that is coherently organized in a way that achieves something" (Meadows 11). Trees are systems. So are football teams, schools, cities, factories, animals, forests, and national economies (11). Systems are composed of feedback loops, structures and behaviors, inputs and outputs, that are operating in multiple directions at the same time. Thinking through and making adjustments to complex systems is an imperfect science because systems, despite our best attempts to grasp them, remain opaque to us on some levels: "the idea of making a complex system do just what you want it to do can be achieved only temporarily, at best. We can never fully understand our world, not in the way that reductionist science has led us to expect (168).

Because systems are not transparent, successful interventions cannot come from authoritarian, inflexible positions. Donna Meadows argues that “we can't find a proper, sustainable relationship to nature, each other, or the institutions we create, if we try to do it from the role of omniscient conqueror" (Meadows 168). Besides being unethical, and 
barbaric, and unjust, that authoritarian inflexibility is ineffectual. If systems are always in motion, so too, must we be.

Institutional spaces are not this dynamic though. According to Punctuated Equilibrium Theory, institutions are "stabilized by their conservative nature" (Treur 24). Stability is maintained by incentivizing existing policies. Those incentives create negative feedback loops that balance the system. However, those negative feedback loops can be changed to positive feedback loops if issues are reframed such that the existing policy is recognized as problematic. Reframing issues to create positive feedback loops results in "dramatic, punctuated changes" that interrupt long periods of stasis (Treur 24).

Systemic issues like climate change and climate injustice cannot be "solved"; they can only be responded to by reframing issues to continually keep up with dynamic systems. The belief that science can or will eventually clarify all that is mysterious or unclear is antithetical to Relation. It is the annihilation of difference and a misrepresentation of what is accomplishable. Aldo Leopold identified this very same problem in his $A$ Sand County Almanac: "The ordinary citizen today assumes that science knows what makes the community clock tick; the scientist is equally sure that he does not. He knows that the biotic mechanism is so complex that its workings may never be fully understood."

Meadows says that we dance with systems rather than controlling them. Glissant might say that we cannot grasp systems, because grasping implies being able to hold them in our hand and bring them to ourselves, to master them. The creative process of generating frameworks to address questions about complex systems like a changing climate and finite natural resources is akin to groping, not grasping: "Groping implies a 
disquiet, an incompleteness; it also has the excitement of discovery, ecstatic transformation, and the advance toward new levels of integration" (Berry 220-221). Groping implies an endlessness; there is never a peace or closure as the problem resolves itself. Instead, there is a bearable tension as we dance with systems in neverending projects to create a more just, equitable, livable world.

To revise an earlier point: communities, both imagined and unimagined, can be reimagined by subverting the institutions that control those narratives and clamoring for political transparency and communal visibility at the same time as they clamor for opacity and grope through uncertainty. The PCM did both, making clear policy demands and celebrating the opacity of different groups and individuals who spoke through their differences rather than flattening them under a universal message. 


\section{NOW WHAT?}

The momentum of a march is expected to extend beyond the duration of a march. After all, "the point of radical democracy is not only to extend equal recognition between recognized and unrecognized groups but to change the relationships that create the state of unimaginability or non-recognization" (Butler, Notes 5). It is not enough that a march allows for momentary recognition of marginalized groups; it must work towards larger systemic changes that prevent these groups from being sidelined in the first place.

A march, as a transient community, can't do all that work during the few hours, on a single day, that citizens take to the streets and form a visible communal body, moving through and asserting itself in a public space. Butler notes that marches are often discussed as almost the avatar of democracy. In fact, a popular call-and-response chant at marches is "Show me what democracy looks like!" "This is what democracy looks like!" Public assembly, as Butler reminds us, does not engage all facets of democracy. Gatherings are not the embodiment of democracy; they are, rather, an embodied act of imaginative democratizing.

Sometimes acts of assembly are made to bear more political or ideological weight than they can carry. If marches, rallies, or protest are expected to create instantaneous change or are charged with being emblematic of entire movements, then it is impossible to count them as successes and it is easy to lance down these straw figures. As with all imaginative endeavors, how success and failure are defined is important. Even if an act of assembly fails to result in concrete policy change, it can still furnish new vocabularies for approaching issues and act as a springboard for future successes. Operating from within and promoting a Poetics of Relation is one such change that can resonate beyond the end 
point of a march. Purdy argues that even policies themselves cannot be held to rigid definitions of success and failure: "Asking simply whether a new approach to climate change will succeed as a lawmaking or regulatory strategy is too narrow...laws and lawmaking are forums where cultural and imaginative innovation happens, innovation that will help to lay the foundation of any future legal regime for climate change" (252)

In Miami, the PCM resulted in clear gains, in policy, community-building, and changing the conversation on climate change. Through the march, the MCA was made possible. During the planning for the march, MCA members discovered that zero of Miami-Dade County's budget dollars were clearly allocated towards climate resilience or mitigation. The political pressure they leveraged and awareness they raised during the 2015-2016 Miami Dade County Budget Hearings (some, by giving statements wearing lifejackets) contributed to the creation of the Miami-Dade Office of Resilience and a new position - Chief Resilience Officer.

Not everyone who marched in 2015, 2016, and 2017 is actively engaged in climate justice initiatives in South Florida. Not everyone who marched together in those years is now fully awakened to climate injustice in the community. But the transient community of the marches has thickened into lasting relationships. What started as a fledging group of like-minded activists has grown into a thriving network.

The MCA website currently defines their mission as such:

“The Miami Climate Alliance's mission is to build urgency, power, and cohesion by activating the Miami community through strategic actions that recognize climate change as a threat multiplier to all forms of justice, especially for low-income frontline communities, and to create a model 
for just, equitable, and resilient communities in the face of climate change by achieving substantive wins that will increase the wellbeing of Miami residents in both the present and future."

It is a pragmatic goal, and a utopian one - an ever-evolving act of collaborative imagination.

And the MCA is only one of many of these acts.

Two weeks ago, I attended a Hackathon where groups came together to design Augmented Reality (AR) apps that allowed users to interface with the Miami Murals Project, a mural series focused on the effects of climate change. The prototype apps created simulations that, for example, allowed users to map flooding, witness the effects of sea-level rise in different areas of the city, and connect with other app users.

At that same Hackathon, I met Ugo Angeletti, a student who started Back2Earth Composting in South Miami, an organic waste collection service where compost bins are picked up on bikes - a small move, as he says, with big impacts ("Our Story").

In April, eight young Floridians brought a lawsuit against the state of Florida for "violating the public trust by failing to protect certain essential natural resources (like beaches) for future generations" (Harris).

In January of 2010, the four counties in South Florida (Monroe, Miami-Dade, Broward, and Palm Beach) formed the Southeast Florida Climate Change Compact (the Compact), an association of Broward, Miami-Dade, Monroe, and Palm Beach Counties that works to organize climate mitigation and adaptation across county lines ("What is the Compact?"). 
In July 2017, former New York City Mayor Michael Bloomberg and California Governor Jerry Brown launched "America's Pledge” which, in the wake of the Trump Administration's decision to pull out of the Paris Climate Agreement, formed a collective of cities, states, businesses, and universities (non-national actors) that pledged to uphold to the carbon emissions reductions the U.S. committed to in Paris ("About America's Pledge").

It is true that "institutional actions (and institutional inaction) have a profound impact on environmental outcomes, most blatantly in relation to climate change, which no collectivized ethical behavior can combat without backing from well-implemented transnational accords" (Nixon 39). It is also true that in the absence of well-implemented transnational accords, imaginative workarounds are all we've got. 


\section{REIMAGINED COMMUNITIES}

Collaborative imaginations are what we need for these murky, Anthropogenic times, where we grapple with hyperobjects too massive to hold in our minds and lurch forward in an increasingly globalized society.

It must be noted that imagination is not a panacea. Climate change will cause suffering that imagination cannot wish away. In Poetics of Relation, Glissant also says that "No imagination helps avert destitution in reality, none can oppose oppressions or sustain those who "withstand" in body or spirit. But imagination changes mentalities, however slowly it may go about this." And imagination is, as Glissant also says, "a palliative for Eternity." Imagination is the chipping away at futures that seem inevitable.

Who will architect these futures? This question is deceptive. What it really means is, who is architecting the present. In Miami, Liberty City and Little Haiti comprise some of the areas of highest elevation. It may not be the ocean that erases them, but developers who are already buying up cheap land, perhaps chuckling about their future beachfront properties. But there are others, imagining different futures.

These others are galvanizing a people's climate movement, which does not ignore the suffering that has occurred and which will occur, but which operates from within a Poetics of Relation - bringing differences together and letting difference speak. A Poetics of Relation is not a chorus of voices; they do not harmonize. These people are not all singing the same tune - some of them prioritize saving pine rockland; others, creating

more sustainable transportation systems. A Poetics of Relation is the most discordant jazz we know, that we still, after all, recognize as music. 
Some of our history and some of our landscapes will be submerged; some things, done, cannot be undone. But what is inundated and what is preserved, what is lost and what is retained, what is prevented and what is reshaped, what communities emerge from these difficult times - this is what we are writing, what we are imagining, now. 


\section{BIBLIOGRAPHY}

“About." Americas Pledge On Climate, www.americaspledgeonclimate.com/about/. Anderson, Benedict R. O'G. Imagined Communities: Reflections on the Origin and Spread of Nationalism. Verso, 2016.

Berry, Thomas. The Dream of the Earth. Counterpoint, 2015

@BillyCorben “Miami Sea-Level Rise Cmte member@BorgesArchitect berates climate activist@SustainableMags, misquotes her, mansplains how she can best focus her energy because she's wasting her time, says "I don't wanna spend an ounce of my energy fighting polluters" because Miami. @MiamiMayor?’Twitter, 4 April 2018, 8:38 a.m., https://twitter.com/BillyCorben/status/981556714146291713

Brulle, Robert J. "Institutionalizing Delay: Foundation Funding and the Creation of U.S. Climate Change Counter-Movement Organizations." Climatic Change, vol. 122, no. 4, 2013, pp. 681-694. ResearchGate, doi:10.1007/s10584-013-1018-7.

Butler, Judith. Notes Toward a Performative Theory of Assembly. Harvard University Press, 2018.

--. "Rethinking Vulnerability and Resistance." Vulnerability in Resistance, by Judith Butler et al., Duke University Press, 2016, pp. 12-27.

Debord, Guy, and Donald Nicholson-Smith. The Society of the Spectacle. Zone Books, 2012.

Diawara, Manthia, director. Edouard Glissant: One World in Relation. Third World Newsreel, 2010.

Feigenbaum, Paul. Collaborative Imagination: Earning Activism Through Literacy Education. Southern Illinois University Press, 2015.

"Future Days Above 95F." Climate Central, 3 Aug. 2017, www.climatecentral.org/gallery/graphics/future-days-above-95f.

Garan, Ron. "The Key Is We.” Ron Garan, www.rongaran.com/the-key-is-we/.

Glissant, Edouard, Poetics of Relation. University of Michigan Press, 2009.

Goodell, Jeff. The Water Will Come: Rising Seas, Sinking Cities, and the Remaking of the Civilized World. Little, Brown and Company, 2017. 
Haraway, Donna Jeanne. Staying With the Trouble: Making Kin in the Chthulucene. Duke University Press, 2016.

Harris, Alex. "Kids Are Suing Gov. Rick Scott to Force Florida to Take Action on Climate Change" Miami Herald, 16 Apr. 2018, http://www.miamiherald.com/news/local/environment/article208967284.html

--. “Should Miami’s Sea Level Rise Committee Address Climate Change, Too?” Miami Herald, 5 Apr. 2018, www.miamiherald.com/news/local/environment/article208034699.html.

Heise, Ursula K. Sense of Place and Sense of Planet: The Environmental Imagination of the Global. Oxford University Press, 2010.

Ianelli, Jerry. "Member of Miami Sea Level Rise Committee Berated Climate Activist Until She Cried." Miami New Times , 2 Apr. 2018, www.miaminewtimes.com/content/printView/10221528.

Leiserowitz, Anthony, et al. "Climate Change in the American Mind: March 2018." Yale Program on Climate Change Communication, 17 Apr. 2018, climatecommunication.yale.edu/publications/climate-change-american-mindmarch-2018/.

LeGuin, Ursula K. "Why Are Americans Afraid of Dragons." Sfublogs Archive, Simon Fraser University, www.sfu.ca/sfublogs-archive/.../02/Why-are-AmericansAfraid-of-Dragons.docx.

Leopold, Aldo, and Michael Sewell. A Sand County Almanac: with Essays on Conservation. Oxford University Press, 2001.

Marshall, George. Don't Even Think About It: Why Our Brains Are Wired to Ignore Climate Change. Bloomsbury, 2015.

McNeill, J.R. Something New under the Sun: An Environmental History of the TwentiethCentury World. Penguin Books, 2001.

Meadows, Donella H., and Diana Wright. Thinking in Systems: A Primer. Chelsea Green Publishing, 2008.

“Mission.” Miami Climate Alliance, miamiclimatealliance.org/mission/.

Morton, Timothy. Hyperobjects: Philosophy and Ecology After the End of the World. University of Minnesota Press, 2014. 
Nixon, Rob. Slow Violence and the Environmentalism of the Poor. Harvard University Press, 2013.

"Our Mission." back2earth, back2earth.io/our-mission/.

"Pay Up Climate Polluters." Pay Up Climate Polluters, www.payupclimatepolluters.org/.

Pressler, Jessica. "The Wooly Mammoth in the Coal Mine." New York Magazine, 23 Mar. 2016, nymag.com/daily/intelligencer/2016/03/inside-faena-house-miamibeach.html.

Purdy, Jedediah. After Nature: A Politics for the Anthropocene. Harvard University Press, 2015.

Rice, Jenny. Distant Publics: Development Rhetoric and the Subject of Crisis. University of Pittsburgh Press, 2012.

Robertson, Roland. "Glocalization: Time-Space and HomogeneityHeterogeneity." Global Modernities Global Modernities, pp. 25-44., doi:10.4135/9781446250563.n2.

"Silencing Science Tracker ." Sabin Center for Climate Change Law, Columbia Law School, columbiaclimatelaw.com/resources/silencing-science-tracker/.

Stein, Kate. "Outburst At Miami Sea-Level Rise Meeting Prompts Discussion On Urgency, Equity." WLRN, 3 Apr. 2018, wlrn.org/post/outburst-miami-sea-levelrise-meeting-prompts-discussion-urgency-equity.

Stocker, Thomas F, et al., editors. Climate Change 2013: The Physical Science Basis (Fifth Assessment Report). UN Intergovernmental Panel on Climate Change, 2013, Climate Change 2013: The Physical Science Basis (Fifth Assessment Report), www.ipcc.ch/report/ar5/wg1/.

Treuer, Galen. "Risk and the Response to Sea Level Rise in South Florida." Open Access Dissertations, University of Miami, 31 July 2017, www.easybib.com/mla8format/dissertation-citation.

"What Is the Compact ." Southeast Florida Regional Climate Compact, www.southeastfloridaclimatecompact.org/about-us/what-is-the-compact/.

Young, Lisa. "Building Solidarity and Growing a Movement : the Story behind the People's Climate March.” DSpace, MIT, June 2015, dspace.mit.edu/handle/1721.1/99083. 